\title{
DOES CLINICAL AND LABORATORY MARKERS ARE PREDICTIVE OF RADIOLOGICAL JOINT DAMAGE IN RHEUMATOID ARTHRITIS?
}

\author{
ABUL KHAIR AHMEDULLAH ${ }^{1}$, ZINAT NASRIN ${ }^{2}$, ABU SHAHIN ${ }^{3}$, SHAMIM AHMED ${ }^{4}$, MINHAJ RAHIM \\ CHOUDHURY5, SYED ATIQUL HAQ ${ }^{6}$
}

\begin{abstract}
Aims and objectives. To identify the association of following variables with radiographic findings in rheumatoid arthritis cases in Bangladesh: Age at onset, Duration of suffering, Sex, Clinical indexes of disease activity \& Rheumatoid factor

Methods. In this observational study, 100 consecutive rheumatoid arthritis patients who met ACR criteria 1987 were enrolled from rheumatology OPD of BSMMU from the period of August 2009April 2010. Clinical evaluations and laboratory investigations were done in all cases. Final evaluation was done on 96 patients, because 4 patients were dropped out, due to inconclusive radiological report. Radiographs of hands and wrists were scored by Van der Heijde modification of Sharp scoring method.

Results. Out of 96 patients 73 were female and 23 male with female male ratio of 3.1:1. Age of onset was $41.0 \pm 11.0$ (mean $\pm S D$ ) in male and $37.7 \pm 12.9$ in female. 90 patients had severe $R A$ among them 21 (23.3\%) were male and 69 (76.6\%) were female. Rose Waaler (RW) test was positive in 68 cases. Bony erosions were observed in 58 cases, out of them 15 (65.2\%) were male and 43 (58.9\%) female. Bony erosions were observed in $60.3 \%$ cases of positive Rose Waaler and $69.8 \%$ in patients whose age at onset was < $45 \mathrm{yrs}$. Hemoglobin level $(\mathrm{gm} / \mathrm{dl})$ was $12.2 \pm 1.6$ in male and $10.9 \pm 1.5$ in female. Platelet count was $312142 \pm 111233$ in male and was $379114 \pm 115574$ in females.

Conclusion: Hemoglobin levels were significantly lower among the anemic women than anemic men. Thrombocytosis was also more in women than men. Higher percentage of bony erosions was observed among the cases of positive $R W$ and whose age at onset was < 45 but it was not statistically significant.
\end{abstract}

Key words: Rheumatoid arthritis, Rheumatoid factor, joint damage.

Received: 17 October 2014

Accepted: 19 December 2014

\section{Introduction:}

Rheumatoid arthritis (RA) is a systemic inflammatory disorder that mainly affects the diarthrodial joints ${ }^{1}$. It is the most common form of inflammatory arthritis. In its typical form RA is a symmetrical, destructive and deforming polyarthritis affecting small and large synovial joints with associated systemic disturbance, a variety of extraarticular features and the presence of circulating antiglobulin antibodies (Rheumatoid factor, $\mathrm{RF})^{2}$. The clinical course of RA is variable, ranging from mild to severe with profound morbidity and mortality. The best predictors of disability areearly age of onset, radiological grade, sex, initial functional class, rheumatoid factor positivity and rheumatoid nodule ${ }^{1}$. Age is the most powerful single predictive variable. As age increases incidence of RA also increases, co-morbid condition also increases. The course of major disability of RA is set in the first few years of disease ${ }^{3}$. Rheumatoid factor is a hallmark of adult onset RA but in many published studies are of series containing few patients to whom RF is not detected $^{4}$. Severe disease, extraarticular manifestations and radiographic progression of joint damage are more frequently observed in seropositive $\mathrm{RA}^{5,6}$. The degree and extent of joint damage as assessed by radiographic techniques constitutes an important measure of outcome in the treatment of RA. Radiological damage progresses at a constant rate ${ }^{7}$ which is the result of chronic joint inflammations and is often considered an important factor in judging the course of RA and

1. Assistant Professor, Department of Medicine, Comilla Medical College, Comilla

2. Junior Consultant, Department of Radiology, National Institute of Ophthalmology, Dhaka

3. Assistant Professor, Department of Rheumatolgy, BSMMU

4. Associate Professor, Department of Rheumatolgy, BSMMU

5. Professor, Department of Rheumatolgy, BSMMU

6. Chairman and Professor, Department of Rheumatolgy, BSMMU

Correspondence: Abul Khair Ahmedullah, Assistant Professor, Department of Medicine, Comilla Medical College, Comilla. Mobile: 01840188247, Email: ahmedullah_a@yahoo.com

Bangladesh J Medicine 2015; 26 : 13-17 
the efficacy of treatment with DMARDs. In advanced disease monitoring the progression of previously existing damage is as important as assessing new abnormalities in previously undamaged joints ${ }^{8}$.

\section{Materials and methods}

In this observational study $100 \mathrm{RA}$ patients who met American College of Rheumatology (1987) criteria were selected. Four patients were dropped out from the study due to inconclusive radiological report. Subsequently all analysis were done with 96 patients. This study was carried out in the Rheumatology wing, department of Medicine, BSMMU. All the X-rays of hands and wrists were interpreted by a Radiologist. The patients were collected during the period of August 2008- April 2009. Inclusion criteria were, all patients must meet American College of Rheumatology (1987) criteria for RA and have onset age > 16 yrs, Radiographs and/or report of radiographs of hands and wrists must be available,

\section{Outcome measures.}

The following parameters were assessed in all patients at study entry: age, sex, duration of symptoms, time between diagnosis and study enrollment, total number of joint involvement (out of 58-joint count, PIP- 10, MCP- 10, wrist- 2, elbow- 2, shoulder- 2, hip- 2, knee- 2, ankle- 2, MTP- 8, IP- 18).

Total number of tender joints, joint tenderness index by Ritchie articular index $(0=$ non-tender, $1=$ tender, $2=$ wincing and $3=$ withdrawal $)^{9}$, total number of swollen joint, Ten point visual analogue scale (VAS) for patient's assessment of pain, patient's global assessment of disease activity score: $1=$ asymptomatic, $2=$ mild, $3=$ moderate, $4=$ severe, $5=$ very severe, physician's global assessment of disease activity score: 1 = asymptomatic, $2=\operatorname{mild}, 3=$ moderate, $4=$ severe, $5=$ very severe, Health Assessment Questionnaire (HAQ), Rose Waaler test, $\mathrm{X}$-ray of the hands and wrists - by scoring system (the van der Heijde modification of the Sharp scoring method), ESR, Hb\%, TC, DC, Urine R/E, Serum Creatinine, SGPT, fasting blood sugar. Early onsetdisease was considered in patients who developed RA before age of 45 years $^{10}$. Assessment of severity: Severe RA if one of the following characteristics was present: HAQ score $>1.25$, total number of erosions $>30$, and number of persistently swollen joints $>4$, number of prescribed second line drugs $>2$, or occurrence of nodules and other extraarticular manifestations ${ }^{11}$. If none of these characteristics was present, patients were classified as having mild RA. HAQ scoring was done by standard Scoring system $^{12,13}$. Radiographs of the hands and wrists (postero-anterior views) were scored according to the van der Heijde modification of Sharp scoring method.

Data analysis. Descriptive measures (Mean and Standard Deviation) were used in analysis. Crossed tabulations were used to find the associations. Finally t-test and chi-square test with Yates correction were done to find out significant association.

\section{Results}

Table1. Out of 96 patients 73 were female and 23 were male with female male ratio of $3.1: 1$. Age of onset was $41.0 \pm 11.0$ (mean \pm SD) in male and $37.7 \pm 12.9$ in female and duration of disease was $4.2 \pm 4.0$ and $6.0 \pm 7.5$ in males and females respectively. Family history was positive in 11 cases. Rose Waaler test was positive in 68 cases. Joint erosions were observed in 58 patients, out of them $15(65.2 \%)$ were male and 43 (58.9\%) female. Hemoglobin \% was $12.2 \pm 1.6$ in males and 10.9+1.5 in females, Platelet Count were 312142 \pm 111233 in males and $379114 \pm 115574$ in females.

Table-I

\begin{tabular}{lccc}
\hline & Total & Male & Female \\
\hline Sex & 96 & $23(23.96)$ & $73(76.04)$ \\
Male: Female ratio & $1: 3.1$ & & \\
Age at onset & $38.5 \pm 12.5$ & $4.2 \pm 4.0$ & $6.0 \pm 7.5$ \\
Duration or Disease & $11(11.5)$ & $22.4 \pm 16.1$ & $21.23 \pm 14.3$ \\
Positive family history & $21.5 \pm 7$ & $7.9 \pm 6.5$ \\
Total joint involved & $7.8+6.5$ & $7.7 \pm 6.9$ & $20.3 \pm 14.7$ \\
Number of Swollen joint & $20.7 \pm 14.9$ & $21.7 \pm 16.1$ & $41.3 \pm 36.2$ \\
Number of Tender joint & $41.8 \pm 37.7$ & $43.4 \pm 42.9$ & $4.9 \pm 2.5$ \\
Tenderness index & $4.8 \pm 2.4$ & $4.5 \pm 2.4$ & $2.8 \pm .9$ \\
Patient assessment of pain (VAS) & $2.8 \pm 0.93$ & $2.8 \pm 1.0$ & $2.8 \pm .9$ \\
Patient global assessment & $2.8 \pm 0.9$ & $2.7 \pm .9$ & $1.26 \pm .7$ \\
Physician global assessment & $1.26 \pm 0.7$ & $1.29 \pm .7$ & $43(58.9)$ \\
HAQ score & $68(70.8)$ & & $30(41.1)$ \\
Rose Waaler positive & $58(60.42)$ & $15(65.2)$ & $7.2 \pm 38.6$ \\
Erosive joint damage & $38(39.58)$ & $8(34.8)$ & $10.9 \pm 1.5$ \\
Non erosive joint & $71.9 \pm 39.4$ & $65.0 \pm 42.0$ & $379114 \pm 115574$ \\
ESR & $11.3 \pm 1.6$ & $312142 \pm 111233$ & 3.6 \\
Hb (gm/dl) & $363659 \pm 117452$ & & \\
Platelet Count & & \\
\hline
\end{tabular}

(Data in the parenthesis indicates percentages and values are described as mean $\pm \mathrm{SD}$ ) 
Table II

Variables were assessed at first visit in male and female patients in tabulated form and significance were tested by $t$-test. There was significant difference between hemoglobin $(\mathrm{gm} / \mathrm{dl})$ and platelet count between male and female.

\begin{tabular}{lccc}
\hline & Male (23) & Female (73) & t- value \\
\hline Age of onset & $41.0+11.0$ & $37.7 \pm 12.9$ & 1.19 \\
Duration of Disease & $4.2 \pm 4.0$ & $6.0 \pm 7.5$ & -1.47 \\
Total joint & $22.4 \pm 16.1$ & $21.23 \pm 14.3$ & .281 \\
Swollen joint & $7.7 \pm 6.9$ & $7.9 \pm 6.5$ & -.109 \\
Tender joint & $21.7 \pm 16.1$ & $20.3 \pm 14.7$ & .347 \\
Tenderness index & $43.4 \pm 42.9$ & $41.3 \pm 36.2$ & .217 \\
Patient assessment of pain (VAS) & $4.5 \pm 2.4$ & $4.9 \pm 2.5$ & -.649 \\
Patient global assessment & $2.8 \pm 1.0$ & $2.8 \pm .9$ & .086 \\
Physician global assessment & $2.7 \pm .9$ & $2.8 \pm .9$ & -.119 \\
HAQ score & $1.29 \pm .7$ & $1.26 \pm .7$ & .223 \\
ESR & $65.0 \pm 42.0$ & $74.2 \pm 38.6$ & -.927 \\
Hb & $12.2 \pm 1.6$ & $10.9 \pm 1.5$ & $3.52^{* *}$ \\
PC & $312142 \pm 111233$ & $379114 \pm 115574$ & $-2.398^{*}$ \\
\hline
\end{tabular}

$* * \mathrm{p}<0.01, * \mathrm{p}<0.05$

Table-III

Radiographic evidence of joint erosion was present in $62.7 \%$ of early age and $55.2 \%$ of late age of onset

\begin{tabular}{lccc}
\hline & Total & $\begin{array}{c}\text { Erosion } \\
\text { present }\end{array}$ & $\begin{array}{c}\text { Erosion } \\
\text { absent }\end{array}$ \\
\hline Age of onset & & & \\
$<45$ & $67(69.8)$ & $42(62.7)$ & $25(37.3)$ \\
$>=45$ & $29(30.2)$ & $16(55.2)$ & $13(44.8)$ \\
Total & 96 & $58(100.0)$ & $38(100.0)$ \\
\hline
\end{tabular}

(Data in the parenthesis indicates percentages) $\mathrm{X}^{*}=0.48, \mathrm{p}=0.49$

\section{Table-IV}

Higher percentage of erosion (60.3\%) was observed among the cases of positive $R W$ but it was not statistically significant.

\begin{tabular}{lccc}
\hline & Total & $\begin{array}{c}\text { Erosion } \\
\text { present }\end{array}$ & $\begin{array}{c}\text { Erosion } \\
\text { absent }\end{array}$ \\
\hline Positive & $68(70.8)$ & $41(60.3)$ & $27(39.7)$ \\
Negative & $28(29.2)$ & $17(60.7)$ & $11(39.3)$ \\
\hline Total & 96 & 58 & 38 \\
\hline
\end{tabular}

(Data in the parenthesis indicates percentages) $\mathrm{X}^{2}=0.969, \mathrm{p}=0.578$

Table-V

The clinical and laboratory variables were analyzed and significance was tested by t-test. There was no significant difference between the variables in erosion present and absent patients.

\begin{tabular}{lccc}
\hline & Erosion present (58) & Erosion absent $(38)$ & t-value \\
\hline Age of onset & $38.1 \pm 12.5$ & $39.1 \pm 12.5$ & -.383 \\
Duration of disease & $6.1 \pm 6.3$ & $4.7 \pm 7.6$ & .893 \\
Total joint & $23.3 \pm 15.0$ & $18.7 \pm 14.0$ & 1.512 \\
Swollen joint & $8.9 \pm 9.6$ & $6.3 \pm 5.8$ & 1.974 \\
Tender joint & $22.3 \pm 15.4$ & $18.2 \pm 14.1$ & 1.332 \\
Tenderness index & $43.8 \pm 38.4$ & $38.8 \pm 36.9$ & .629 \\
Patient assessment of pain (VAS) & $5.1 \pm 2.6$ & $4.4 \pm 2.2$ & 1.386 \\
Patient global assessment & $2.9 \pm .9$ & $2.6+. \mathrm{S}$ & 1.759 \\
Physician global assessment & $2.9 \pm 1.0$ & $2.6 \pm .7$ & 1.861 \\
HAQ score & $1.3+.7$ & $1.2+.6$ & .969 \\
ESR & $76.3 \pm 41.5$ & $65.0 \pm 35.3$ & 1.419 \\
Hb & $11.1 \pm 1.6$ & $11.5 \pm 1.4$ & -1.559 \\
PC & $375905.6 \pm 120813.3$ & $346579 \pm 111930$ & 1.192 \\
$* * \mathrm{p}<0.01,{ }^{*} \mathrm{p}<0.05$ & & &
\end{tabular}


Table-VI

Joint erosions were present in $65.2 \%$ male and $58.9 \%$ female patients. Comparison by chi square $\left(X^{2}\right)$ test did not show any significant difference.

\begin{tabular}{lccc}
\hline & Total & Erosion present & Erosion absent \\
\hline Male & $23(24.0)$ & $15(65.2)$ & $8(34.8)$ \\
Female & $73(76.0)$ & $43(58.9)$ & $30(41.1)$ \\
Total & 96 & $58(100)$ & $38(100)$ \\
\hline
\end{tabular}

(Data in the parenthesis indicates percentages) $\mathrm{X}^{2}=0.29, \mathrm{p}=0.589$

\section{Table-VII}

6 patients had mild $R A$ and 90 patients had severe $R A$. Among the patients of severe diseases 21 (23.3\%) were male and 69 (76.6\%) were female. The result is not statistically significant.

\begin{tabular}{lccc}
\hline & Total & Male & Female \\
\hline Severity & & & \\
Mild & $6(6.3)$ & $2(33.3)$ & $4(66.7)$ \\
Severe & $90(93.8)$ & $21(23.3)$ & $69(76.6)$ \\
Total & $96(100)$ & $23(100)$ & $73(100)$ \\
\hline
\end{tabular}

(Data in the parenthesis indicates percentages) $\mathrm{X}^{2}=0.004$ (Yates correction), $\mathrm{p}=0.95$

Table-VIII

Among the patients of severe diseases 55 (61.1\%) had erosive damage. Among the patients of mild diseases 3

(50\%) had erosive damage. The result is not statistically significant.

\begin{tabular}{lccc}
\hline & Total & Erosion present & Erosion absent \\
\hline Severity & & & \\
Mild & $6(6.3)$ & $3(50.0)$ & $3(50.0)$ \\
Severe & $90(93.7)$ & $55(61.1)$ & $35(38.9)$ \\
Total & $96(100)$ & $58(100)$ & $38(100)$ \\
\hline
\end{tabular}

(Data in the parenthesis indicates percentages)

$\mathrm{X}^{2}=0.01$ (Yates correction), $\mathrm{p}=0.91$

\section{Discussion}

Out of 96 cases 73 were female and 23 male with female to male ratio $3.1: 1$ which is similar to most of the studies ${ }^{14,15}$. We observed mean age of onset of RA in the study population is 38.5 years, in whom mean age of onset in male cases were 41 years and in female cases were 37 years, which is consistent with most of the studies ${ }^{16,17}$. Analysis of clinical and laboratory variables between male and female cases showed no significant difference except hemoglobin
$\%$ and platelet count. Hemoglobin \% was significantly lower and platelet count was significantly higher in females than males. Hochberg et al 1988 showed that hemoglobin levels were significantly lower among the anemic women than anemic men which are consistent with our observation ${ }^{18}$. Higher percentage of bony erosions were observed among rheumatoid factor positive patients but comparison between erosion present and absent cases did not show any statistically significant difference. Van Zeben et al, observed that patients with a persistently positive RF test, irrespective of the type of test used, had more radiological abnormalities ${ }^{11}$. Fuchs et al 1989 , observed that radiographic scores were strongly correlated with duration of disease but we did not find any significant difference ${ }^{19}$.

\section{References}

1. David LE, Michael WE.. Rheumatoid arthritis. The Lancet, 2001; 358: 903-11.

2. Majithia V, Geraci SA. "Rheumatoid arthritis: diagnosis and management”. Am. J. Med. 2007; 120 (11): 936-9.

3. Sherrer SY, Bloch AD, Mitchell MD, Young YD, Freis FJ. The development of disability in rheumatoid arthritis. Arthritis and Rheumatism, 1986; 29: 494-500.

4. Gao X, Fernandez-Vina M, Olsen JN, Pincus T, Stastny P. HLA-DPB1*0301 is a Major Risk Factor for Rheumatoid Factor-Negative Adult Rheumatoid Arthritis. Arthritis \& Rheumatism; 1991; 34: 1310-1312.

5. de Vries-Bouwstra JK, Goekoop-Ruiterman YP, Verpoort KN, Schreuder GMT, Ewals JAPM,Terwiel JP, Ronday HK, Kerstens PJSM, Toes REM, de Vries RRP, Breedveld FC, Dijkmans BAC, Huizinga TWJ, Allaart CF. Progression of joint damage in early rheumatoid arthritis: association with HLA-DRB1, rheumatoid factor, and anti-citrullinated protein antibodies in relation to different treatment strategies. Arthritis Rheum; 2008; 58:1293.

6. Vander Heijde MFM Desiree, Leeuwen A. Van Miek, Van Riel L.C.M. Piet, Koster M. Anja, Hof Vant A, Marless, Risurik Van H. Marlies, Putte Van De, B.A. Lerrnus. Biannual radiographic assessments of hands and feet in a 3 years prospective follow up of pts with early rheumatoid arthritis. Arthritis and Rheumatism, 1992; 35: 26-34.

7. Paimela L. The radiographic criterion in the 1987 revised criteria for rheumatoid arthritis. Arthritis and Rheumatism, 1992; 35: 255-258.

8. Hulsmans MJH, Johannes W. G. Jacobs WGJ, Van Der Heijde MFMD, Van Albada-Kuipers AG, Schenk Y, Bijlsma WJJ. The course of radiologic damage during the $1^{\text {st }} 6$ years of rheumatoid arthritis. Arthritis and Rheumatism, 2000; 43:1927-1940. 
9. Ritchie MD, Boyle AJ, Mclnnes MJ, Jasani KM, Dalakos GT, Grieveson P, Bchanan WW. Clinical Studies with an articular index for the assessment of joint tenderness in patients with rheumatoid arthritis. Quarterly journal of medicine; 1968; 147: 393-406.

10. Thomson W, Harrison B, Ollier B, Wiles N, Payton T, Barrett J, Symmons D, Silman A. Quantifying the exact role of HLA-DRB1 alleles in susceptibility to inflammatory polyarthritis: Results from a large, population-based study. Arthritis \& Rheumatism; 1999; 42: 757-762.

11. van Zeben $\mathrm{D}, \mathrm{J}$ M Hazes MJ, Zwinderman HA, Cats $A$, van der VAE, Breedveld CF. Clinical significance of rheumatoid factors in early rheumatoid arthritis: results of a follow up study. Ann of Rheum Dis, 1992; 51: 1029-1035

12. Pincus T, Sumey A Jane, Salvatore A, Soraci Jr., Waltston A, Kenneth, Hummon P. Norman. Assessment of patient satisfaction in activities of daily living using a modified Stanford health assessment questionnaire. Arthritis and Rheumatism, 1983; 26: 1346-1353.
13. Pincus T, Swearingen C, Wolfe F (1999). Toward a multidimensional health assessment questionnaire (MDHAQ). Arthritis and Rheumatism, 42:2220-2230.

14. Kvien TK, Uhlig T, Ødegård S, Heiberg MS (2006). Epidemiological aspects of rheumatoid arthritis: the sex ratio. Ann N Y Acad Sci.;1069:212-22.

15. Jawaheer, Lum RF, Gregersen PK, and Criswell LA (2006). "Influence of Male Sex on Disease Phenotype in Familial Rheumatoid Arthritis," Arthritis \& Rheumatism; (DOI: 10.1002/art.22120).

16. Masi AT, Robert T. Chatterton RT, Aldag JC (2009). Hypothalamic-Pituitary-Gonadal Axis Hormones and Male Rheumatoid Arthritis: Novel Perspectives. The Journal of Rheumatology; 36(5): 859-862.

17. Amador-Patarroyo MJ, Rodriguez-Rodriguez A, Montoya-Ortiz G (2012). How Does Age at Onset Influence the Outcome of Autoimmune Diseases? Autoimmune Diseases; 2012:1-7.

18. Hochberg MC, Arnold CM, Hogans BB, Spivak JL (1988), Serum immunoreactive erythropoietin in rheumatoid arthritis: impaired response to anemia. Arthritis \& Rheumatism, 31: 1318-1321.

19. Fuchs HA, Kaye JJ, Callahan LF, Nance EP, Pincus $T$ (1989). Evidence of significant radiographic damage in rheumatoid arthritis within the first 2 years of disease. J Rheumatol;16:585-91. 